\title{
Study of effects of seawater salt spray on growth, chlorophyll fluorescence and chlorophyll content in three coastal species of Morocco
}

\author{
A. Kouali ${ }^{1 *}$, M. Mouradi ${ }^{2}$, L. Latrach ${ }^{2}$, A. Khadraji ${ }^{2}$, O. Elasri ${ }^{3}$, Z. Baicha ${ }^{4}$, \\ A. Berrichi ${ }^{1}$, N. Kouddane ${ }^{1}$ and A. Boukroute ${ }^{1}$ \\ ${ }^{1}$ Laboratoire de production végétale, Université Mohammed Premier, Faculté des Sciences, Oujda, Maroc. \\ ${ }^{2}$ Cadi Ayyad University, PO Box 2390, Marrakesh, Morocco. \\ ${ }^{3}$ Biochemistry and Biotechnology Laboratory, Mohamed First University, Oujda, Morocco. \\ ${ }^{4}$ Laboratory of Mechanics and Industrial Processes, ENSET, Mohammed V University, 10100 Rabat, Morocco.
}
Received 28 Feb 2016
Revised 02 May 2016,
Accepted 07 May 2016

\section{Keywords \\ $\checkmark$ Araucaria heterophylla, \\ $\checkmark$ chlorophyll content, \\ $\checkmark$ chlorophyll fluorescence, \\ $\checkmark$ Lagunaria patersonii, \\ $\checkmark$ salt spray, \\ $\checkmark$ Schinus terebinthifolius}

Correspendance :

kouali.abdellah@gmail.com

(A. Kouali).

\begin{abstract}
Plants of the coastal areas are frequently subjected to salt stress due to the continuous exposure of those plants to wind of seawater. The experiment was conducted under greenhouse. Three ornamental species (Lagunaria patersonii, Schinus terebinthifolius and Araucaria heterophylla) were used in this work. Two salt spray treatments were applied for three months, once a day (T1) and twice a day (T2). During the experiment, the plants height, the number of ramifications, the chlorophyll fluorescence $\left(\mathrm{F}_{\mathrm{v}} / \mathrm{F}_{\mathrm{m}}\right)$, and the chlorophyll content were examined. The results showed that after ninety days, the seawater spraying decreased plants height, ramifications, $F_{v} / F_{m}$ and chlorophyll content in all of the studied species with significant variation between them. Based on these results, A. heterophylla was qualified as more tolerant to salt spray, its survival rate was higher than $94 \%$, while $L$. patersonii and S. terebinthifolius were presented only $91 \%$ and $83 \%$ respectively. In terms of the studied parameters, tolerance to salt spray may strongly associate with great photosystem II (PSII) performance and high chlorophyll content under this constraint. In addition, salt spray may prevent L. patersonii, S. terebinthifolius from growing in these coastal areas.
\end{abstract}

\section{Introduction}

Salt is a natural nutrient for all living beings, as well as plants. However, in large quantities, the salt is toxic and has even fatal effects on plants via the accumulation of high dose of sodium or chlorine [1]. This becomes a problem for grown plants in the coastal environments, where the salinity of the ocean dissipated tiny droplets of sodium chloride in the air [2]. Several reports revealed the severity of the salt spray in coastal areas for some plants species [3, 4]. High salt spray could entirely remove less salt-tolerant species such as $P$. taeda [5]. Various forms of plant responses to adverse effects of salt were studied, two groups were defined: species are more tolerant remain unaffected in their different development phases and susceptible species with low salt concentration [6]. Ewe et al., [7] indicated that S. terebinthifolius presented good physiological responses with its important biomass and leaf area to high salinity stress. A. heterophylla and L. patersonii are also commonly grown species in the coastal areas in many countries [8]. The abusive high salt spray negatively affects either the rhizosphere, the aerial part of the plant, limits their distribution in natural habitats [9] and often leads to vegetation zonation [10]. Similarly, soil salinity and water deficit [11] decrease the growth and survival of plants in coastal areas. In the physiological traits, high salt concentration adversely affects photosynthesis process [12]. Indeed, the presence of salt in the rhizosphere negatively disrupts nutrient uptake, enzymatic activities, cells membrane stability, leaf chlorophyll content and water status [13].

Chlorophyll fluorescence is a recent effective physiological method to study the photosynthetic state of plants and their responses to environmental abiotic stresses such as salinity and water deficit $[12,14,15]$. The changes of the photosystem II (PSII) performance under these constraints may determine the degree of tolerance of the ornamental plants in coastal areas before any morphological damages take place. 
In order to preserve green spaces, essentially in salty coastal areas, this study aims to select and evaluate the appropriate ornamental species to these special environments. This paper investigated the response and the adaptability of tree ornamental species: Schinus terebinthifolius, Araucaria heterophylla and Lagunaria patersonii to seawater spray.

\section{Materials and methods}

\subsection{Plant material and experimental conditions}

Plants of the ornamental species (Schinus terebinthifolius, Araucaria heterophylla and Lagunaria patersonii) (10 months from the seed) were grown under greenhouse conditions in the experimental station of the Faculty of Sciences Oujda, Morocco. These species are commonly used as roadside trees in the green spaces of the Moroccan coastal areas and many other countries [8]. The plants were transferred to plastic bags $(35 \mathrm{~cm} \times 18$ $\mathrm{cm}$ ). Each bag filled with a mixture of sand, soil and peat (organic maters $=23.3 \%, \mathrm{pH}=6.7$, electrical conductivity $=2.67 \mathrm{mS} . \mathrm{cm}^{-1}$ ) with the proportion of 2:1:2 respectively. Plants were watered daily with distillated water quantity calculated according to the reel evapotranspiration $\left(\mathrm{ET}_{0}\right)$ (Table 1).

Table 1: Means of $\mathrm{ET}_{0}$ from June to September 2013/2014.

\begin{tabular}{|c|c|}
\hline Months & $\mathrm{ET}_{0}(\mathrm{~mm})$ \\
\hline June & $6 \pm 0.5$ \\
\hline July & $7.1 \pm 1$ \\
\hline August & $6.9 \pm 0.1$ \\
\hline September & $5.3 \pm 0.7$ \\
\hline
\end{tabular}

For the salt stress treatments, $2 / 3$ of the plants of each species were subjected to seawater spray (electrical conductivity $=185.4 \mathrm{mS} . \mathrm{cm}^{-1}$, salt concentration $=114 \mathrm{~g} . \mathrm{Kg}^{-1}$ ) during three months. Half of these plants was subjected to treatment $\mathrm{T} 2$ by leaf spraying twice a day (morning and evening), while the other half was subjected to treatment $\mathrm{T} 1$ by sprayed only once a day (morning). The further plants did not receive any treatment and considered as controls (T0). Twelve plants were considered per treatment per species. The salt treatments were performed using a spray system (sprayer) until appearance of droplets on the leaves. The plants roots were not exposed to seawater. Therefore, we focused on the effects of seawater spray on the aerial parts.

\subsection{Plants height and ramifications}

The plants height was measured using a graduated ruler. New branches were counted to assess the effect of seawater spray on ramifications. The values are the average of five repetitions per species per treatment.

\subsection{Chlorophyll fluorescence measurement}

The quantum yield of the PSII was measured using a portable fluorimeter (Handy PEA, Hansatech, England). The leaves were dark adapted for 15 to $20 \mathrm{~min}$ before measurement. The chlorophyll fluorescence is defined as the $F_{v} / F_{m}$ ratio $=\left(F_{m}-F_{o}\right) / F_{m}[16]$, where $F_{v}$ is the variable fluorescence, $F_{m}$ is the maximum fluorescence and $F_{o}$ is the fluorescence signal received from the leaves. This parameter is used to indicate the variation of the PSII under abiotic stress. Ten plants per treatment per species were considered and grouped as three replicates.

\subsection{Total chlorophyll content}

Chlorophyll (Chl) content was determined according to Arnon [17]. It was extracted with acetone in a mortar, using $200 \mathrm{mg}$ of fresh leaf and $5 \mathrm{~mL}$ of acetone $(80 \%$, v/v). After centrifugation $(5000 \times \mathrm{g}$ for $7 \mathrm{~min})$, the chlorophyll content was determined in the supernatants using a spectrophotometer at optical densities (OD) of 663 and $645 \mathrm{~nm}$ respectively and calculated using the formula: $\mathrm{Chl}\left(\mathrm{mg} \cdot \mathrm{g}^{-1} \mathrm{FM}\right)=\left(8.02 \times \mathrm{OD}_{663}+20.2 \times \mathrm{OD}_{645}\right)$. Ten plants per treatment per species were considered and grouped as three replicates.

\subsection{Statistical analysis}

The experiment was carried out in a complete randomized block design. The two-way analysis of variance (ANOVA II) using IBM SPSS 21.0 software (SPSS, Chicago, Illinois, USA, 2012). The means were compared using Tukey's test at the significance level of $\alpha=0.05$. Figures were created using Microsoft Excel. 


\section{Results}

3.1. Effect of seawater spray on plants height and ramification

Results showed that salt spray (T1 and T2) decreased the plants height and ramifications respectively in almost all of the studied ornamental species with significant $(\mathrm{p}<0.001)$ variation between them (Table 1,2$)$. The reductions were more pronounced at the end of the experiment in comparison to the start. For the plants height, the highest reduction of $26.8 \%$ was observed in $L$. patersonii under T1 treatment, whereas under T2, L. patersonii and $S$. terebinthifolius presented the highest reductions of $28.5 \%$ and $17.2 \%$ respectively. In both treatments (T1 and T2), A. heterophylla seems to be not affected. For the number of ramifications, the highest reductions of $95.5 \%$ and $41.5 \%$ were noted in S. terebinthifolius and L. patersonii respectively under T1, while the lowest reduction of $16.6 \%$ was presented by A. heterophylla. Under T2 treatment, L. patersonii and A. heterophylla presented reductions of $31.4 \%$ and $37.5 \%$ respectively, while S. terebinthifolius presented the most severe reduction of $98.9 \%$ at the end of the experiment.

Table 2: Effect of salt treatments on plants height $\left(\mathrm{cm}\right.$. plant $\left.^{-1}\right)$ of A. heterophylla, L. patersonii and S. terebinthifolius species. Values are means of three replicates (six plants each) \pm standard.

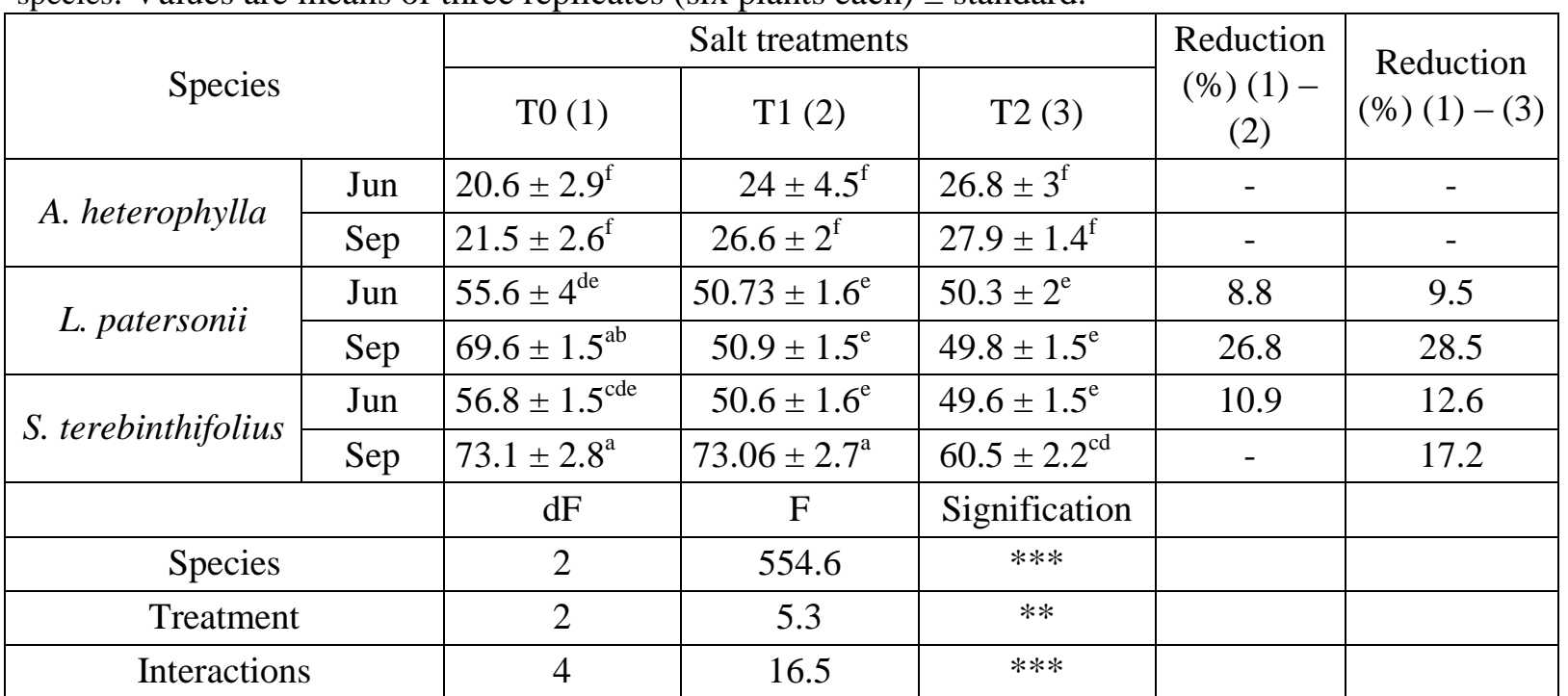

Notes: *: Significance at 0.05 probability level; **: Significance at 0.01 probability level; ***: Significance at 0.001 probability level; NS: Not significant at 0.05 . Letters are significance at 0.05 probability using post hoc Tukey's tests. dF: degree of freedom; F: Fisher value; -: No reduction.

Table 3: Effect of salt treatments on the number of ramifications.plant ${ }^{-1}$ of A. heterophylla, L. patersonii and S. terebinthifolius species. Values are means of three replicates (six plants each) \pm standard.

\begin{tabular}{|c|c|c|c|c|c|c|}
\hline \multirow{2}{*}{\multicolumn{2}{|c|}{ Species }} & \multicolumn{3}{|c|}{ Salt treatments } & \multirow{2}{*}{$\begin{array}{l}\text { Reduction } \\
(\%)(1)-(2)\end{array}$} & \multirow{2}{*}{$\begin{array}{l}\text { Reduction } \\
(\%)(1)-(3)\end{array}$} \\
\hline & & T0 (1) & $\mathrm{T} 1(2)$ & $\mathrm{T} 2(3)$ & & \\
\hline \multirow{2}{*}{ A. heterophylla } & Jun & $18 \pm 2.6^{\mathrm{ijk}}$ & $21 \pm 1^{\mathrm{hij}}$ & $18 \pm 2.6^{\mathrm{ijk}}$ & - & - \\
\hline & Sep & $26.6 \pm 1.1^{\mathrm{e}-\mathrm{i}}$ & $22.3 \pm 2.5^{\mathrm{hij}}$ & $16.6 \pm 3.2^{\mathrm{jk}}$ & 16.6 & 37.5 \\
\hline \multirow{2}{*}{ L. patersonii } & Jun & $41.6 \pm 3.7^{\mathrm{b}}$ & $29.6 \pm 3^{\text {d-h }}$ & $43.6 \pm 6.3^{\mathrm{b}}$ & 28.8 & - \\
\hline & Sep & $53 \pm 3^{\mathrm{a}}$ & $31 \pm 3.4^{\mathrm{def}}$ & $36.3 \pm 4.5^{\mathrm{bcd}}$ & 41.5 & 31.4 \\
\hline \multirow{2}{*}{ S. terebinthifolius } & Jun & $20.3 \pm 1.5^{\mathrm{ij}}$ & $33 \pm 3^{\text {cde }}$ & $38.6 \pm 3.2^{\mathrm{bc}}$ & - & - \\
\hline & Sep & $29.3 \pm 2.5^{\mathrm{bc}}$ & $1.3 \pm 1.1^{1}$ & $0.3 \pm 0.5^{1}$ & 95.5 & 98.9 \\
\hline & $\mathrm{dF}$ & $\mathrm{F}$ & Signification & & \\
\hline \multicolumn{2}{|l|}{ Species } & 2 & 60.1 & $* * *$ & & \\
\hline \multicolumn{2}{|l|}{ Treatment } & 2 & 8.4 & $* * *$ & & \\
\hline \multicolumn{2}{|l|}{ Interactions } & 4 & 2.9 & NS & & \\
\hline
\end{tabular}

Notes: *: Significance at 0.05 probability level; **: Significance at 0.01 probability level; ***: Significance at 0.001 probability level; NS: Not significant at 0.05 . Letters are significance at 0.05 probability using post hoc Tukey's tests. dF: degree of freedom; F: Fisher value; -: No reduction. 


\subsection{Chlorophyll fluorescence}

According to ANOVA test (Table 4), salinity significantly $(\mathrm{p}<0.001)$ decreases the $\mathrm{F}_{\mathrm{v}} / \mathrm{F}_{\mathrm{m}}$ ratio in all of the studied species with significant $(\mathrm{p}<0.001)$ variation between them (Figure 1). In response to $\mathrm{T} 1$, the $\mathrm{F}_{\mathrm{v}} / \mathrm{F}_{\mathrm{m}}$ for $A$. heterophylla started to significantly $(\mathrm{p}<0.05)$ decrease according to Tukey's test in Aug and raised in Sep with a values of 0.35 and 0.44 respectively, while under $T 2$, the values of $F_{v} / F_{m}$ significantly $(p<0.05)$ decreased and varied from 0.31 to 0.28 from Jul to Sep. For L. patersonii, salt spray (T1 and T2) significantly ( $<0.001)$ decreases the $\mathrm{F}_{\mathrm{v}} / \mathrm{F}_{\mathrm{m}}$ ratio from the start of the experiment to the end according to Tukey's test. Under T2, the reductions were more severe especially at the end of the test; $L$. patersonii presented $\mathrm{F}_{\mathrm{v}} / \mathrm{F}_{\mathrm{m}}$ values of 0.26 and 0.29 respectively in Aug and Sep. S. terebinthifolius was also significantly $(\mathrm{p}<0.001)$ decreased the $\mathrm{F}_{\mathrm{v}} / \mathrm{F}_{\mathrm{m}}$ under both salt spray treatments, especially in the last three months of the test. Under $T 1$, the $F_{v} / F_{m}$ values were 0.35 . 0.35 and 0.32 , while under T2, the values were $0.19,0.24$ and 0.25 respectively in Jul. Aug and Sep.
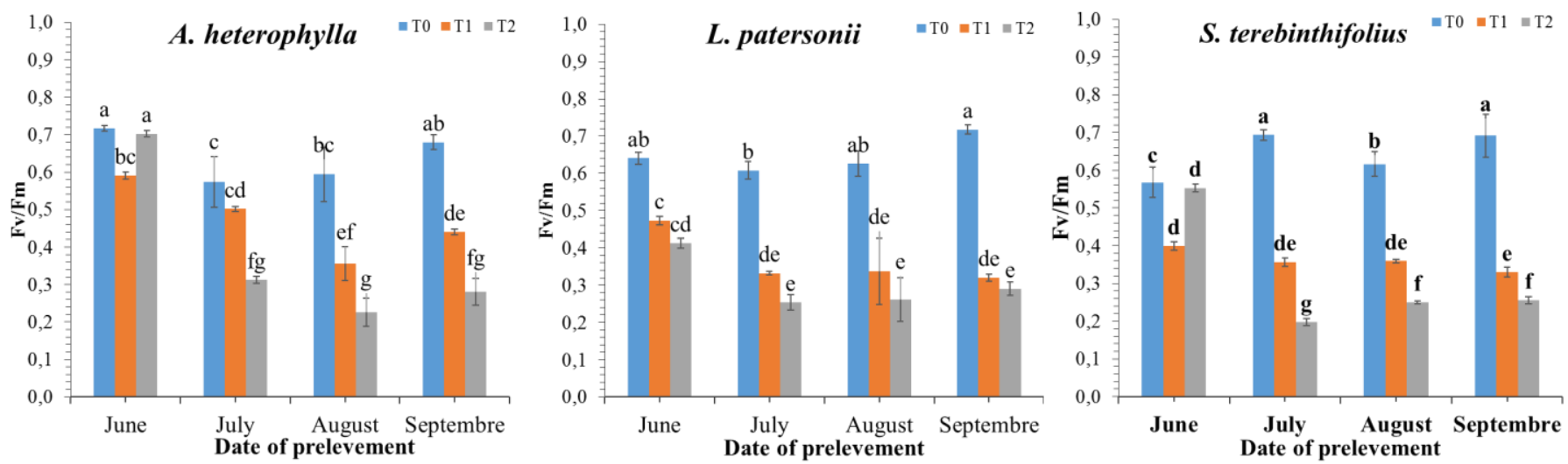

Figure 1: Effect of salt treatments on the $F_{\mathfrak{v}} / F_{m}$ of A. heterophylla, L. patersonii and S. terebinthifolius. Values are means of three replicates (six plants each) \pm standard. Letters are significance at 0.05 probability using post hoc Tukey's tests.

\subsection{Chlorophyll content}

The results showed that the chlorophyll content was negatively affected by seawater treatments in all of the studied species (Table 4, Figure 2). The treated plants T2 showed the lowest values compared to those T1. A. heterophylla presented the lowest chlorophyll reductions of $44.7 \%$ and $54.78 \%$ respectively under $\mathrm{T} 1$ and $\mathrm{T} 2$ among all of the studied species at the end of the experiment. Similarly, L. patersonii was severally $(\mathrm{p}<0.001)$ affected by salt treatments. According to Tukey's test, the most significant falls of the chlorophyll content were noted in Jul. The chlorophyll concentrations in Sep were $0.57 \pm 0.04$ and $0.30 \pm 0.01 \mathrm{mg} . \mathrm{g}^{-1}$ FM respectively for $\mathrm{T} 1$ and T2. For S. terebinthifolius, there were a significant $(\mathrm{p}<0.001$, Table 4$)$ decrease in the Chl content started from Jul and continued to Sep as response to the salt treatments. The severity of this constraint has been increased significantly $(\mathrm{p}<0.05)$ at the end of the experiment according to Tukey's test. This species has presented the highest reductions of $88.8 \%$ and $94 \%$ under $\mathrm{T} 1$ and $\mathrm{T} 2$ respectively.
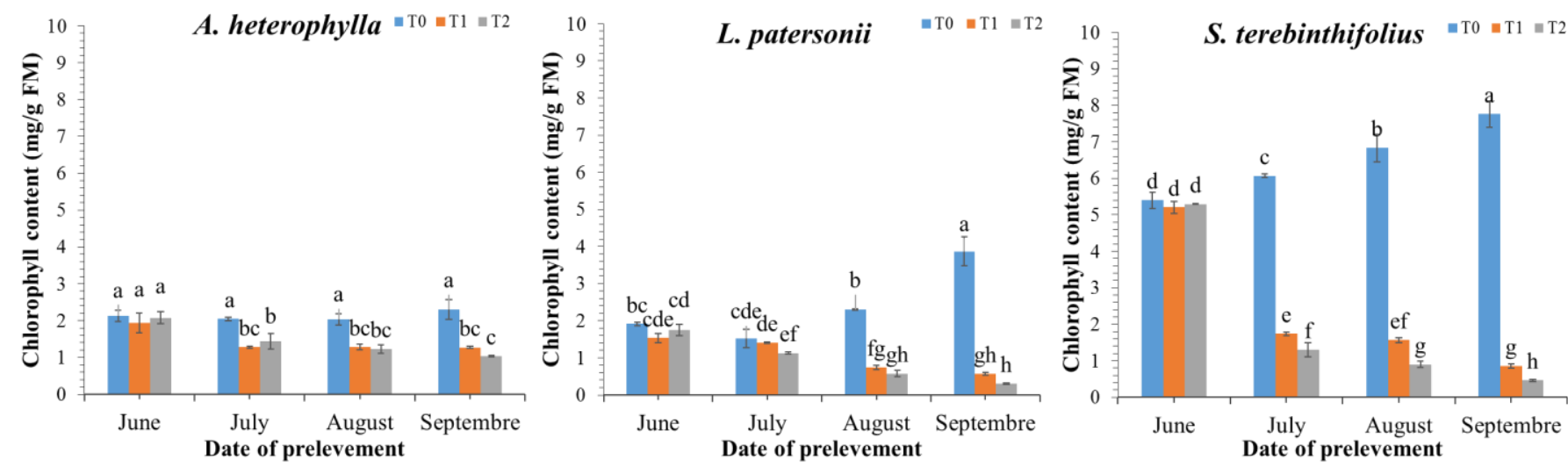

Figure 2: Effect of salt treatments on the leaf chlorophyll content of A. heterophylla, L. patersonii and S. terebinthifolius species. Values are means of three replicates (six plants each) \pm standard. Letters are significance at 0.05 probability using post hoc Tukey's tests. 
Table 4. Results of two-way analysis of variance (ANOVA II) of salt treatments and studied species effects and their interactions for the considered parameters.

\begin{tabular}{|c|c|c|c|c|c|c|}
\hline \multirow{2}{*}{ Dependent variables } & \multicolumn{6}{|c|}{ Independent variables } \\
\cline { 2 - 7 } & \multicolumn{2}{|c|}{ Species } & \multicolumn{2}{c|}{ Treatment } & \multicolumn{2}{c|}{ Interactions } \\
\cline { 2 - 7 } & $\mathrm{dF}$ & $\mathrm{F}$ & $\mathrm{dF}$ & $\mathrm{F}$ & $\mathrm{dF}$ & $\mathrm{F}$ \\
\hline $\mathrm{F}_{\mathrm{v}} / \mathrm{F}_{\mathrm{m}}$ & 2 & $40.6^{* * *}$ & 2 & $946.8^{* * *}$ & 4 & $13^{* * *}$ \\
\hline Chlorophyll content & 2 & $1908.8^{* * *}$ & 2 & $2088.7^{* * *}$ & 4 & $573.6^{* * *}$ \\
\hline
\end{tabular}

Notes: *: Significance at 0.05 probability level; **: Significance at 0.01 probability level; ***: Significance at 0.001 probability level; NS: Not significant at 0.05 . dF: degree of freedom; F: Fisher value.

\section{Discussion}

In the present study, the results showed that seawater spray decreased the plants height and ramifications in all of the studied species with significant variation between them. It is well known that salinity negatively affects plants growth and metabolism. In fact, similar effects of salt spray treatment on plant height and growth has been observed in many plants species such as $P$. rigida and $Q$. rubra $[3,12,18]$. The survival rate of the tree-studied species was $94 \%, 91 \%$ and $83 \%$ for A. heterophylla, L. patersonii and S. terebinthifolius respectively.

Generally, plants have developed several morphological and physiological strategies to survive under salt stress [19]. In this study, the degree of tolerance to salinity significantly varies from species to others and as a result, the responses to this stress were statistically different (Table 4). Griffiths and Orians (2004), have reported similar results for Pinus rigida in terms of growth and ramifications [4]. For A. heterophylla, there was no significant reduction in the plant height in comparison to the other species, this may due to its great adaptability to these conditions.

Furthermore, the plants that have lost their leaves will tend to produce a fresh leaf to reward for the losses, if the conditions will permit, but in our case, the sprayed plants were not able to grow because the seawater spray was continuous throughout the experience. Leaves burning and curling followed these reductions especially in $S$. terebinthifolius. The leaves curling presented by S. terebinthifolius and L. patersonii during the salt treatments could be explained as an adaptation strategy to face this stressful situation. Under this condition, those plants curl their leaves and reduce area in order to avoid salt deposits, and to minimize the water loss by transpiration. Some authors, Latrach et al. and Kekere et al. [12, 20], published similar findings for Medicago sativa, Kyllinga peruviana and Paspalum vaginatum respectively. A. heterophylla was more tolerant to stress due to its high survival rate (more than 90\%) under salt treatment, this could be explained by the structure of their leaves (leavesscales), which permit it to resist the seawater spray [21]. The complete shutdown of the growth and development of plants under the constraint of seawater is explained by the reduction in the leaves number and by consequence the decrease in photosynthesis rate. The same effect has been reported in Aleppo pine grown in the Tunisian coastline [20].

Seawater spray negatively affected the chlorophyll fluorescence in all of the studied species with significant variation in their behaviors $(\mathrm{p}<0.05)$. Generally, plants in normal conditions presented the ratio $\mathrm{F}_{\mathrm{v}} / \mathrm{F}_{\mathrm{m}}$ close to 0.8 but in our case, the decrease of $F_{v} / F_{m}$ was positively correlated with the salt spray. This parameter is considered as one of efficient tools for determination of the plants stress response, particularly before any morphological changes showing up for many plants species whether or not the PSII damages occurred in the leaves [23]. Some researchers have not found any changes in the first days of salt stress [11], while other reported significant decreases in the $F_{v} / F_{m}$ under severe salinity and drought [24]. Mouradi et al., [14] and Fghire et al., [15] proved the efficiency of this tool for determining more drought tolerant genotypes of alfalfa and quinoa respectively. As well as drought, PSII performance decreased under salinity reflected by the decrease in the $F_{v} / F_{m}$ ratio [12]. These results are essentially linked to the photosynthetic state engendered by seawater spray as results of stomatal closure and water loss by osmotic stress [25].

Furthermore, the reduction in the number of leaves and their sizes acts negatively on the interception of the light and by consequence the decrease in the chlorophyll content owing to the presence of $\mathrm{NaCl}$, which deteriorates the leaf's cuticle, disrupts the stomata and disintegrate the chloroplasts [26]. In addition, the chlorophyll damage is might be due to the potassium $\mathrm{K}^{+}$deficiency occurred during the treatment, which was inversely correlated to the increase of the amount of the sodium $\mathrm{Na}^{+}$ion, this indicates competition effect between the $\mathrm{Na}^{+}$and $\mathrm{K}^{+}$ions [27]. Based on these results, A. heterophylla conserved higher PSII performance and Chlorophyll content in its leaves then the other species. With the observed leaf curling and other osmotic adjustment mechanisms as response to 
salinity stress we suggests that it may constitute an adaptation strategy to avoid high salt stress disadvantages in photosynthetic metabolism [28].

\section{Conclusion}

The experimental evidences presented in this study suggest that seawater spray causes multiple physiological responses inside the studied plants. Growth and the photosynthetic parameters significantly decreased as response to sweater spray. Obtained results also demonstrated that species responses to salt stress differ significantly under both salt spray treatments. A. heterophylla was qualified as more tolerant to seawater spray treatments, while $S$. terebinthifolius was qualified less salt spray tolerant. L. patersonii has shown intermediate tolerance. The degree of tolerance was associated to the maintain of high chlorophyll content and $\mathrm{F}_{\mathrm{v}} / \mathrm{F}_{\mathrm{m}}$ ratio even under salt stress.

\section{References}

1. Saadallah K., Drevon J.J., Abdelly C., Agronomie, 21 (2001) 627-634.

2. Ferrante A., Trivellini A., Malorgio F., Carmassi, G., Vernieri, P., Serra, G., Sci. Hortic. 128 (2011) 332341.

3. Griffiths M. E., and Orians C. M., Am. J. Botany. 90 (2003) 1720-1728.

4. Griffiths M. E., and Orians C. M., J. Torrey Bot. Soc. 131 (2004) 23-31.

5. Wells B. W., Shunk I. V., Torrey Bot. 65 (1938) 485-493.

6. Rajesh A., Arumugam R., and Venkatesalu V., Photosynthetica. 35 (1998) 285-287.

7. Ewe, S. M., and Sternberg, L. D. S. L., Trees, 19(2) (2005) 119-128.

8. Kuruneri-Chitepo, C., and Shackleton, C. M., Urban Forestry \& Urban Greening, 10(3) (2011) 247-254.

9. Sánchez-blanco M. J., Rodríguez P., Olmos E., Morales M., Torrecillas A., J. Environ. Qual. 33 (2004) 1369-1375.

10. Randall R. E., J. Ecology. 58 (1970) 155-172.

11. Smith V. R., Steenkamp M., J. Veg. Sci. 12 (2001) 181-198.

12. Latrach L., Farissi M., Mouradi M., Makoudi B., Bouizgaren A., and Ghoulam C., Turk. J. Agric. For. 38 (2014) 320-326.

13. Kaya C., Sönmez O., Aydemir S., Dikilitaş M., Turk. J. Agric. For. 37 (2013) 188-194.

14. Mouradi M., Farissi M., Bouizgaren A., Makoudi B., Kabbadj A., Very A. A., Sentenac H., Qaddoury A., and Ghoulam C., Arid Land Res. Manag. 30(2) (2016) 193-208.

15. Fghire R., Anaya F., Ali O. I., Benlhabib O., Ragab R., and Wahbi S., Chil. J. Agric. Res. 75 (2015) 174183.

16. Jifon J. L., Syvertsen J. P., Tree Physiol. 23 (2003) 119-127.

17. Arnon D. I., Plant Physiology. 24 (1949) 1-15.

18. Parida A. K., Das A. B., Mohanty P., J. Plant Physiol. 161 (2004) 531-542.

19. Lopez M., Herrera-Cervera J. A., Iribarne C., Tejera, N. A., and Lluch C., J. Plant Physiol. 165 (2008) 641650.

20. Kekere O., J. Plant Studies. 3 (2014) 2.

21. Veillon J. M., Candollea. 35 (1980) 609-640.

22. Becker M., Programme DEFORPA, 2e rapport, ENGREF, (1991) 25-41.

23. Waldhoff D., Furch B., Junk W. J., Environ. Exp. Bot. 48 (2002) 225-235.

24. Akram M., Farooq S., Afzaal M., Naz F., Arshad R., Pak. J. Bot. 38 (2006) 1739-1743.

25. Naumann J. C., Young D. R., Anderson J. E., Environ. Exp. Bot. 63 (2008) 402-409.

26. Touchette B. W., Rhodes K. L., Smith G. A., and Poole M., Estuar. Coast. 32 (2009) 917-925.

27. Al Karaki G. N., J. Plant Nutr. 23 (2000) 1-8.

28. Ben Yahmed J, Novillo P, Garcia-Lor A, Salvador A, Ben Mimoun M, Luro F, Talon M., Ollitraut P., Morillon R., Sci. Hort. 191 (2015) 90-100.

(2017), http://www.jmaterenvironsci.com 